\title{
The Foundations of Freezeout Laws in Takeovers
}

\author{
Yakov Amihud Marcel Kahan Rangarajan K. Sundaram*
}

August 20, 2003

\begin{abstract}
We provide an economic basis for permitting freezeouts of non-tendering shareholders following successful takeovers. We describe a specific freezeout mechanism based on easily verifiable information that induces desirable efficiency and welfare properties in models of both corporations with widely dispersed shareholdings and corporations with large pivotal shareholders. The mechanism dominates previous proposals along some important dimensions. We also examine takeover premia that arise in the presence of competition among raiders. Our mechanism is closely related to the practice of takeover law in the U.S.; thus, our analysis may be thought of as analyzing the economic foundations of current regulations.
\end{abstract}

\footnotetext{
${ }^{*}$ Amihud and Sundaram are from the Department of Finance, Stern School of Business, New York University, New York, NY 10012. Kahan is from the School of Law, New York University, New York, NY 10012. We thank Rick Green (the Editor), Oliver Hart, Holger Mueller, and Roberta Romano for their input. We are especially grateful to an anonymous referee for detailed comments and suggestions on earlier versions of this paper.
} 
Grossman and Hart (1980) point out that free-riding considerations could thwart takeovers of widely-held corporations where each shareholder is negligibly small. Anticipating that the post-takeover value of the raider-run firm will exceed the tender price, target shareholders prefer holding on to their shares and free-riding on the raider's improvement in firm value to tendering. Thus, no shareholder tenders and raids fail even if they are valueincreasing. Grossman and Hart argue that to enable takeovers to succeed, an exclusionary mechanism is needed that deters free-riding by "punishing" non-tendering shareholders.

The economic desirability of an exclusionary mechanism depends on more than just its deterrence of free-riding. By influencing the likelihood of successful takeovers, the mechanism affects the incentives of raiders to mount takeovers and of incumbent managers to generate firm value and so determines overall welfare. Efficiency considerations further demand that an exclusionary device promote value-enhancing takeovers (those where the value of the raider-run firm exceeds the value under current management) and discourage value-decreasing ones. These issues were at the heart of the Grossman-Hart analysis but have received little attention in the subsequent literature; we return to them in this paper.

We consider an exclusionary mechanism that is based on a particular "freezeout" of nontendering shareholders. Under our rule, in the event of a successful takeover, non-tendering shareholders receive the maximum of two values: (a) the target company's share price immediately prior to the tender offer, and (b) the tender offer itself. This simple rule has several valuable properties. First, it induces a unique equilibrium whose outcomes coincide in all respects with those resulting under the optimal dilution mechanism of Grossman and Hart. Second, the two values required for its implementation, the offer price and the stock price, are observable and verifiable. Third, it is consistent with the law and practice of actual tender offers in the U.S.; indeed, our analysis may be viewed as an examination of the economic underpinnings of the U.S. legal structure governing takeovers.

Our analysis begins with the framework of Grossman and Hart (1980) who consider a firm with widely dispersed shareholdings. The only exogenous variable in this model is the 
ex ante distribution of values of the firm under the raider's control. Other quantitiesthe firm value under incumbent management, the probability of a successful raid, and the firm's pre-offer share price - are determined endogenously as functions of the exclusionary device. Grossman and Hart propose an exclusionary device based on dilution: A successful raider may transfer to himself a fixed dollar amount from the post-takeover firm value. If dilution lowers the residual value of the firm below the tender price, free-riding is inhibited. Grossman and Hart identify and characterize the optimal level of dilution in the model.

We show that our freezeout rule induces a unique equilibrium in this model whose outcomes coincide in all respects with those resulting under the optimal dilution mechanism of Grossman and Hart. In particular, takeovers succeed when, and only when, they are value-enhancing; and the same ex ante firm value results as under the optimal dilution mechanism.

The Grossman-Hart mechanism, however, has three important shortcomings that are not present in our solution. First, to ensure that shareholders do not tender at any price, such as below the firm's value under incumbent management, Grossman and Hart impose an ad-hoc lower bound on admissible tender offers. This bound eliminates inefficient valuereducing takeovers by its very definition, but it depends on information that is unverifiable, and arguably even unobservable, by a third party such as a court of law. Absent this bound, new equilibria arise that are inefficient. Multiplicity of equilibria also creates ambiguity in defining a single optimal level of dilution: What level is optimal will depend on which equilibrium is actually played.

Second, even if the lower bound on admissible offers is preserved, Bagnoli and Lipman (1988) show that if conditional and restricted tender offers are considered, the Grossman-Hart mechanism admits inefficient equilibria in which value-reducing takeovers can succeed. Intuitively, dilution enables a wealth transfer from minority shareholders to the raider that could be used to subsidize payments to tendering shareholders. Such inefficiencies cannot arise under our rule since non-tendering shareholders receive at least as much 
in the freezeout as those who tender. Third, the form of dilution proposed by Grossman and Hart is infeasible in practice since it is in violation of U.S. law.

Our rule is notably more "benevolent" to target firm shareholders than the GrossmanHart mechanism which works by threatening non-tendering shareholders with dilution of their post-takeover wealth. Such threats create what Bebchuk and Hart (2001) call "pressure to tender" and could lead to excessive tendering. The lower bound on offers imposed by Grossman and Hart is precisely to counteract this effect. In contrast, our rule does not penalize non-tendering shareholders compared to those who tender; rather, it eliminates free-riding by limiting the gains to not tendering.

We also examine the impact of our freezeout mechanism on modifications of the Grossman-Hart framework that have been proposed in the literature. These include large shareholdings (Bagnoli and Lipman (1988)), asymmetric information concerning the value of a raider-run firm (Shleifer and Vishny (1986)), post-takeover moral hazard (Burkart, Gromb, and Panunzi (1998)), and risk-arbitrage (Cornelli and Li (2001)). In each case, it was shown that free-riding can be resolved without exclusion, but that outcomes without exclusion may be inefficient. We find that when freezeouts are introduced into these models, the modifications have no effect; in each case there is a unique equilibrium which is also efficient.

A counterfactual implication of introducing our freezeout rule into the Grossman-Hart model and its modifications is that the takeover premium is zero in equilibrium. (The Grossman-Hart dilution mechanism also carries this implication.) In the final part of the paper, we examine the Fishman (1989) model of competition among several raiders. Preemptive bidding by the first raider, and Bertrand competition among raiders if more than one raider enters, results in a positive takeover premium in equilibrium. Reflecting the expected takeover premium, the firm's pre-offer share price exceeds its value under current management. Efficiency demands, however, that takeovers succeed whenever the raiderrun firm is worth more than firm value under current management. Thus, an exclusionary 
device can be efficient only if it allows some takeovers to succeed even at prices below the pre-offer share price, that is, at a negative takeover premium. Since negative takeover premia are unreasonable, we propose an alternative criterion of constrained efficiency. An exclusionary mechanism is constrained-efficient if takeover attempts are made and succeed whenever a raider values the firm at more than its pre-offer share price. We show that the freezeout mechanism is constrained efficient.

Freezeouts have been incorporated in other models in the literature. Fishman (1989) looks at a setting with multiple raiders and assumes that shareholders tender to the raider offering the higher price provided this price exceeds a threshold level. Formally incorporating freezeouts into his model would result in identical equilibria as Fishman recognizes (see his footnote 4). More recently, Burkart, Gromb, and Panunzi (1998), Ravid and Spiegel (1999) and Gomes (2001) have all studied models with freezeouts. ${ }^{1}$ Burkart, Gromb and Panunzi examine a model with post-takeover moral hazard; we discuss their paper in Section IV. Ravid and Spiegel are concerned with the optimal toehold acquisition strategy in a model where rival bidders could enter. Gomes studies the takeover premium in a setting which endogenizes the entry of risk-arbitrageurs and their holdings. ${ }^{2}$

The objectives of these papers differ from ours. Fishman, Ravid and Spiegel, and Gomes each take the freezeout rule as given and employ it in deriving their results. Their primary concern is not with the welfare/efficiency implications of the rule as compared to other exclusionary mechanisms, but on other issues; e.g., Gomes considers the effect on the takeover premium of the majority needed to effect a freezeout. Our paper studies the optimality of freezeouts as a mechanism for mitigating free-riding and characterizes its $e x$ ante and ex post effects.

The remainder of this paper is organized as follows. Section I presents the model. Section II derives the equilibrium under our freezeout mechanism and discusses its properties in the original model and extensions. Section III presents the Grossman-Hart mechanism and compares it to ours. Section IV examines the issue of takeover premia. Section V pro- 
vides a description of US takeover law and relates our freezeout rule to the law. Section VI concludes.

\section{The Basic Model}

Our basic model is essentially the framework of Grossman and Hart (1980). We consider a firm with a large number of individually negligible shareholders. In determining their response to the raider's tender offer, shareholders ignore the impact of their own actions on overall outcomes.

The firm is potentially a takeover target. ${ }^{3}$ The cost to the raider of mounting the raid is denoted $c$. The takeover is successful if at least 50 percent of the shares are tendered to the raider. In the event of a successful takeover, the value of the raider-run firm is $v$ (all values are in per-share terms). Ex ante, $v$ and $c$ are random variables with exogenously given distributions, but by the time of the takeover bid, their realizations are known and are common knowledge. ${ }^{4}$

The value of the firm under current management, denoted $q$, is determined as a function of the actions of the firm's manager before the raider's tender offer is made. These actions depend on the likelihood of a successful takeover and are chosen with knowledge of the distribution (but not the realizations) of $v$ and $c$. Specifically, there is a set of actions $A$ available to the manager, and action $a \in A$ leads to the value $q(a)$ for the firm and the utility level $u(a)$ for the manager. We rewrite the manager's utility directly as a function of $q$ by defining ${ }^{5}$

$$
U(q)=\max \{u(a) \mid q(a)=q\}
$$

$U$ is assumed to be continuous as a function of $q$. In the event of a takeover, the manager suffers a utility loss. His utility in this case is denoted $U_{0}$; without loss of generality, we take $U_{0}=0$. Thus, if $\pi$ denotes the probability of a successful takeover, the manager's expected utility is

$$
E U(q)=(1-\pi) U(q)
$$


The manager sets $q$ to maximize his expected utility. This is a non-trivial problem since $\pi$ itself depends on $q$ : ceteris paribus, a higher $q$ reduces the likelihood of a successful takeover. In addition, $\pi$ also depends on the distribution of the variables $v$ and $c$, and on the exclusionary mechanism in place that determines payoffs to non-tendering shareholders in the event of a takeover (see below). The manager takes these dependencies into account in determining $q$.

\section{A. Takeover Offers and Exclusion}

The tender price offered by the raider is denoted $p$. In this initial segment, we focus on "any-and-all" offers in which the raider agrees to buy the shares tendered by any shareholder at the offered tender price of $p$ regardless of how many others tender. ${ }^{6}$

Consider the outcome for a shareholder who does not tender. If the takeover attempt fails, the current management remains in charge, and a non-tendering shareholder receives $q$. If the attempt succeeds, payoffs depend on the exclusionary mechanism in place; this mechanism specifies how non-tendering shareholders are treated following a successful takeover. Absent any exclusionary mechanism, a non-tendering shareholder participates fully in the post-takeover value of the firm and receives $v$. At the opposite extreme, if the exclusionary mechanism allows total dilution of non-tendering shareholders, the latter receive nothing. At this point, we make no specific assumptions regarding exclusion.

Given an exclusionary mechanism, shareholders compare the value of tendering to not tendering and choose the action with the higher value. If shareholders are indifferent, then either action is optimal, and we make no special assumptions concerning their behavior in this case.

\section{B. Pre-Takeover Share Prices}

Given a choice of $q$, the pre-takeover market price of the firm's shares, denoted $r$, is determined as a function of: the value of the firm $q$ under current management; the 
probability of a successful takeover $\pi$; the probability $\theta$ that a tender offer is made which is unsuccessful; the payoffs received by the shareholders in the event of a successful takeover (which depends on the exclusionary mechanism); and the payoffs received by shareholders in the event of an unsuccessful tender offer (which is $p$ for the shareholders who tender and $q$ for those who do not). We assume that the market is risk-neutral with respect to the activities of the firm; thus, $r$ is given by

$$
\begin{array}{r}
r=(1-\pi-\theta) q+\theta E[\text { Shareholder payoffs } \| \text { unsuccessful tender offer }] \\
+\pi E[\text { Shareholder payoffs } \| \text { successful tender offer }]
\end{array}
$$

Note that $r$ is the share price of the firm before it is known whether a takeover will occur.

C. Ex-Ante Firm Value

The value of the firm is given by $q$ if there is no successful takeover and by $v$ if there is a successful takeover. Since resources of $c$ are consumed in the takeover process, the ex-ante value of the firm net of takeover costs is given by

$$
R=(1-\pi-\theta) q+\theta(q-c)+\pi E[v-c \| \text { takeover is successful }]
$$

In the sequel, we refer to (4) as simply the ex-ante firm value. Grossman and Hart refer to (4) as a measure of "social welfare."

\section{Efficiency}

An exclusionary mechanism is (ex-post) efficient if and only if all value-enhancing takeovers succeed, i.e., takeovers are attempted and succeed whenever $v-c>q$ and no takeovers are attempted when $v-c<q$. At the "indifference" point $v-c=q$, it makes no difference for efficiency if takeovers are attempted and succeed or if they are not attempted. 


\section{E. Verifiability}

To ensure implementability of an exclusionary mechanism, we require it to be based only on verifiable information. This means that while the mechanism may depend on the share price $r$ (which, in turn, depends on the mechanism), it cannot depend directly on $q$ or $v$. As a first step, we examine outcomes when there is no exclusionary mechanism.

\section{F. The Free-Rider Problem}

When there is no exclusionary device, we obtain the free-rider problem of Grossman and Hart (1980): ${ }^{7}$

Proposition 1 [The Free-Rider Problem]: For any $c>0$, there is no rational expectations equilibrium in which takeover attempts are made and succeed with certainty.

Proof: If $p<v$, a shareholder who believes the raid will succeed is better off not tendering his shares. But then no shareholder tenders, so the raid fails. An offer $p \geq v$ leads to a loss for the raider since $c>0$, so such an offer will not be made.

Proposition 1 has been interpreted as an argument that exclusion is necessary for takeovers of widely held corporations to succeed, but, as Bagnoli and Lipman (1988) point out, this is problematic. While raids cannot succeed with certainty without exclusion, they cannot fail with certainty either if $p>q$ since a shareholder who believes the raid will fail with certainty is better off tendering and receiving $p$. If shareholders randomize, outcomes may be deterministic (if an analog of the strong law of large numbers holds) or stochastic (Feldman and Gilles (1985) and Judd (1985) show that a continuum of iid random variables may generate stochastic outcomes). In the former case, the game has no equilibrium at all, so it does not mean much that there is no equilibrium with successful takeovers. In the latter, takeovers succeed probabilistically, and Bagnoli and Lipman show that the raider makes strictly positive profits in equilibrium. 
Free-riding and exclusion have nonetheless remained major concerns of researchers since Grossman and Hart. In the sections following, we present our proposed solution and contrast it with other proposals.

\section{A Freezeout-Based Resolution}

In a freezeout, the shares of non-tendering shareholders are bought out by the raider following a successful takeover at a price determined by pre-specified rules. In this paper, we propose the following freezeout rule: in the event of a successful bid, non-tendering shareholders receive

$$
\max \{r, p\}
$$

where $p$ is the tender price and $r$ is the firm's pre-offer share-price. This rule is based on observable and verifiable information. ${ }^{8}$ In Section V, we show that it is consistent with the law and reflects the payoffs received in the US by non-tendering shareholders. A related rule that has been posited (e.g., Gomes (2001)) is that non-tendering shareholders receive $p$ in a freezeout; we comment on the differences in Section II.C below. Our focus in this section and the next is on the theoretical properties of using (5) as an exclusionary device. We begin with its implications for efficiency of outcomes.

\section{A. The Freezeout Rule and Efficiency}

Proposition 2: Equilibrium outcomes under (5) are efficient. In particular, takeover attempts are made and succeed when $v-c>q$, and no takeover attempts are made when $v-c<q$.

Proof: We first take $r$ and $q$ as given, look at the offer/tendering subgame and show that we must have $p=r=q$ in equilibrium. Then, using this, we show that in equilibrium

the raider makes a tender offer and the tender offer succeeds with certainty when $v-c>q$ and that the raider makes no tender offer when $v-c<q$. 
Let $r$ and $q$ be given. Under (5), an offer $p<\min \{r, q\}$ can never be part of an equilibrium: No shareholder will tender since accepting results in a payoff of $p$, but not tendering leads to either $q$ (if the offer fails) or $\max \{r, p\}=r$ (if it succeeds). If an offer $p>\max \{r, q\}$ is made, the unique continuation equilibrium outcome is for the raid to succeed. However, such an offer cannot be part of an equilibrium either because for any such $p$, there is $p^{\prime}$ such that $\max \{r, q\}<p^{\prime}<p$ which also succeeds with certainty and which is preferable for the raider. Thus, any equilibrium offer $p$ lies in the interval $[\min \{r, q\}, \max \{r, q\}]$.

Consider any equilibrium. Let $\pi$ be the probability of a successful takeover in equilibrium and let $\theta$ be the probability that an offer is made that is unsuccessful. Then, the equilibrium share price $r$ is given by (3). Since the tender offer in equilibrium lies in the interval $[\min \{r, q\}, \max \{r, q\}]$, so too do shareholders' payoffs in a successful tender offer. In an unsuccessful tender offer, shareholders who tender receive $p$ and those who do not receive $q$; once again, therefore, all shareholders' payoffs lie in the same interval. Using the upper-bounds in (3), we have

$$
r \leq(1-\pi-\theta) q+(\pi+\theta) \max \{r, q\}
$$

which implies $r \leq q$. Using the lower bounds in (3), we also have

$$
r \geq(1-\pi-\theta) q+(\pi+\theta) \min \{r, q\}
$$

which implies $r \geq q$. Thus, $r=q$, which means in equilibrium we must have $p=r=q$.

Now, note that the raider will make a tender offer of $p$ only if $v-c \geq p$, since a successful tender offer is unprofitable otherwise. We first show that when $v-c>p$, the raider's equilibrium offer of $p(=r=q)$ succeeds with certainty, i.e., $\theta=0$. To this end, note that when the offer succeeds, the raider's payoff is $v-c-p$, and when 
it fails, the raider's payoff is $-c$. Thus, the raider's expected payoff from the offer $p$ is $(1-\theta)(v-c-p)-\theta c=(1-\theta)(v-p)-c$.

Suppose $\theta>0$. Pick any $\epsilon$ such that $0<\epsilon<\theta(v-p)$ and suppose the raider instead makes a tender offer of $p^{\prime}=p+\epsilon$. Since $p^{\prime}>\max \{r, q\}$, the unique equilibrium outcome is that the raid succeeds with certainty, so the raider's payoff is $v-c-p^{\prime}$ which strictly dominates the payoff from making a tender offer of $p$. This contradicts the definition of $p$ as an equilibrium offer and establishes that in equilibrium tender offers succeed with certainty when $v-c>p$.

When $v-c=p$, there are two equilibria possible. In one, the raider makes a tender offer of $p$ and the raid succeeds with certainty. Note that it cannot be an equilibrium in this case for the raider to enter if he anticipates the raid failing with positive probability since the raider's payoff then is $(1-\theta)(v-c-p)-\theta c=-\theta c<0$. In the other equilibrium, anticipating failure of the raid, the raider does not make a tender offer.

Summing up, we have the following: (a) If $v-c>q$, the raider makes a bid of $p=q$, and the bid succeeds, (b) if $v-c<q$, no takeover bid is mounted, and (c) if $v-c=q$, either a takeover attempt is made that succeeds with certainty or no takeover attempt is made. This completes the proof of the proposition.

Note that in all successful takeovers in Proposition 2, shareholders are indifferent between tendering and not tendering their shares. Takeovers succeed in these cases not because we assume that shareholders tender when they are indifferent, but because tendering is an equilibrium outcome under our freezeout rule (5). Secondly, if (as is common in practice) the tender offer is any-and-all conditional on at least 50 percent tendering, the proof of Proposition 2 remains valid and even gets simplified since all shareholders then receive $q$ if the takeover fails. Two further remarks are important: 
Remark 1 The proof makes no use of the assumption that shareholders are atomistic. Thus, the equilibrium is unchanged even if there are (possibly many) large shareholdings.

Remark 2 The equilibrium is unaffected by whether $v$ is common or private knowledge. Under (5), tendering shareholders receive $p$ while non-tendering shareholders receive either $\max \{r, p\}$ (if the raid succeeds) or $q$ (if it fails). These payoffs do not depend on shareholders' estimates of $v$, so neither will their acceptance/rejection decision.

In the next subsection, we draw on these observations to comment on some extensions of the Grossman and Hart model studied in the literature. We close this subsection by completing the description of equilibrium under (5). For expositional simplicity, we will assume as in Grossman-Hart that at the indifference point $v-c=q$, the raider does not enter. From the proof of Proposition 2, the equilibrium probability of a successful takeover, given $q$, is

$$
\pi(q)=\operatorname{Prob}\{(v, c) \| v-c>q\}
$$

Thus, the incumbent manager of the firm picks $q$ to solve

$$
\max _{q \in \mathbb{R}}(1-\pi(q)) U(q)
$$

The solution $q^{*}$ to $(9)$ is the equilibrium firm value under incumbent management. From (8), the equilibrium probability $\pi^{*}$ of a successful takeover is $\pi^{*}=\pi\left(q^{*}\right)$. This now determines the level of ex-ante firm value $R^{*}$ in the equilibrium as

$$
R^{*}=\left[1-\pi^{*}\right] q^{*}+\pi^{*} E\left[v-c \| v-c>q^{*}\right] .
$$


Section III relates these outcomes to Grossman and Hart's optimal dilution level.

\section{B. Further Implications of the Freezeout Rule}

It has been shown in the literature that such factors as large shareholdings, asymmetric information and risk-arbitrage can resolve the free-rider problem without exclusion but may create inefficiency in outcomes. Since freezeouts are in fact admitted by US law, we examine the impact of these factors under (5). We find that none of these factors now has an impact: equilibria with and without these factors coincide and are efficient. A short discussion follows.

Bagnoli and Lipman (1988) show that if the set of shareholders is finite, there are always Nash equilibria of the game without exclusion in which takeovers succeed (see also Bebchuk (1989)). However, there are multiple equilibria, some of which are in mixedstrategies. Under the latter, outcomes are stochastic so value-increasing takeovers fail with positive probability. Proposition 2 and Remark 1 show that the freezeout rule (5) eliminates such inefficiencies and unambiguously improves outcomes.

In Shleifer and Vishny (1986), the raider is also the sole large shareholder and there is asymmetric information between the raider and the other shareholders about $v$. The raider's being a large shareholder helps resolve the free-rider problem without exclusion, but asymmetric information creates possible inefficiencies in outcomes. Remarks 1 and 2 show that if the freezeout rule (5) is introduced into this model, neither factor matters and outcomes are efficient.

Cornelli and Li (2001) endogenize the presence of large shareholders by having riskarbitrageurs acquire blocks. They show that this resolves the free-rider problem, but outcomes may be inefficient because risk-arbitrageurs fail with positive probability to acquire the necessary stake for the takeover to succeed. Under the freezeout rule (5), however, risk-arbitrage has no role in their model and inefficiency vanishes. 
The case of Burkart, Gromb, and Panunizi (1998), who study a model with post-takeover moral hazard, is more complex. We comment on their paper in detail in Section IV.

\section{Related Freezeout Rules}

An alternative freezeout rule mentioned in the literature is where non-tendering shareholders can be bought out at $p$ rather than $\max \{r, p\}$. This makes inefficient outcomes theoretically possible: In addition to the equilibrium identified in Proposition 2 (which remains an equilibrium here), it is readily seen that there is a second equilibrium in which all shareholders tender at any offer $p$ (including those below $q$ ). The lower bound of $r$ in our rule eliminates this equilibrium. Intuitively, as the proof of Proposition 2 shows, this bound forces $r$ up to at least $q$, so an offer which exceeds $r$ also exceeds $q$ and value-reducing takeovers are avoided.

These observations indicate that it is the presence of $r$ (rather than $p$ ) in the freezeout mechanism that ensures efficiency in our basic model, and indeed, it is easy to check that Proposition 2 is unaffected if non-tendering shareholders are frozen out at the pre-offer share price $r$ rather than at $\max \{r, p\}$. (This point was raised by the referee.) For these two freezeout rules to produce different equilibria, two conditions must hold simultaneously in equilibrium: (i) $p>r$, as happens when there are multiple raiders competing (see Section IV), and (ii) at least some shareholders do not tender in successful takeovers and receive the lower compensation $r$ as a consequence. Under rational expectations, the second condition requires frictions that take us beyond the scope of this paper. ${ }^{9}$

\section{The Grossman-Hart Dilution Mechanism}

This section examines the exclusion device of Grossman and Hart (1980). We look mainly at any-and-all offers, the setting of the Grossman-Hart model, and identify weaknesses of the Grossman-Hart rule that do not arise under our freezeout rule. At the end of 
the section, we note a further weakness of the Grossman-Hart rule pointed out by Bagnoli and Lipman (1988) in the context of restricted offers and show that this problem too does not arise under our rule.

The Grossman-Hart device works by dilution: A successful raider may transfer an amount $\phi$ from the firm to himself, reducing the post-takeover firm value to $\max \{v-\phi, 0\}$. Thus, shareholders tender if

$$
p \geq \max \{v-\phi, 0\}
$$

Grossman and Hart then impose an additional constraint on admissible tender offers which eliminates one form of inefficiency by definition:

$$
p \geq q
$$

From (11) and (12), a successful bid must satisfy $p \geq \max \{v-\phi, q\}$. It is easily seen that if $\min \{\phi, v-q\}>c$, there is a unique rational expectations equilibrium in which the raider makes an offer of $p=\max \{v-\phi, q\}$ and all shareholders tender. The raider's net profit is

$$
v-\max \{v-\phi, q\}-c=\min \{\phi, v-q\}-c .
$$

Thus, dilution resolves the free-rider problem. The choice of $\phi$ affects equilibrium outcomes through its impact on the probability $\pi$ of a successful raid and on the choice of $q$ by incumbent management. From (13), the probability of a successful raid given $\phi$ and $q$, is

$$
\pi(\phi, q)=\operatorname{Prob}\{(v, c) \mid \min (\phi, v-q)>c\}
$$

The firm value $q$ under incumbent management is determined as

$$
q(\phi)=\arg \max _{q}(1-\pi(\phi, q)) U(q)
$$


and the ex-ante firm value given $\phi$ resolves as

$$
R(\phi)=[1-\pi(\phi, q(\phi))] q(\phi)+\pi E[v-c \| \min \{\phi, v-q(\phi)\}>c] .
$$

Grossman and Hart (1980) establish the central result that

Proposition 3: The values $q$ and $R$ are both maximized at $\phi=+\infty$.

Proof: See Grossman and Hart (1980, Proposition 1, p.51, and Proposition 5, p.55).

Proposition 3 shows that ex ante firm value optimality is achieved when the raider can divert the entire post-takeover value of the target firm to himself. Outcomes are also efficient with $\phi=\infty$ : The raider then bids $p=q$ in any takeover attempt, and the attempt succeeds with certainty; from (13), this is profitable for the raider if and only if $v-c>q$.

However, this solution to the free-rider problem has an important weakness: It is inconsistent with observed behavior and violative of the law. The following result is, therefore, of interest. It shows that our solution, which is legally admissible, produces equilibrium outcomes that are literally identical to the optimal Grossman-Hart dilution rule.

Proposition 4: Let $q(\infty)$ and $R(\infty)$ denote the equilibrium values of $q$ and $R$ in the Grossman and Hart optimal solution. Then, $q(\infty)=q^{*}$ and $R(\infty)=R^{*}$, where $q^{*}$ and $R^{*}$ are the equilibrium values under the freezeout rule (5) identified in (9) and (10), respectively.

Proof: With $\phi=+\infty$ and any $q$, the probability of a successful takeover in the Grossman-Hart solution is $\pi(\infty, q)=\operatorname{Prob}\{(v, c) \mid v-q>c\}$. Thus, the optimization problem of the Grossman-Hart manager is

$$
\max _{q}(1-\pi(\infty, q)) U(q)
$$

This optimization problem (17) is identical to the problem (9) faced by the manager in our solution. Thus, the equilibrium values of $q$ coincide in the two solutions. The conditions 
determining successful takeovers also coincide. Thus, all equilibrium values, including the ex-ante firm value $R$, are identical, completing the proof.

A second weakness of the Grossman and Hart mechanism is its information requirements. Permissible bids in the model must meet (12), which depends on $q$. It is doubtful if $q$ may be regarded as even observable, let alone verifiable, by an outside entity such as a court of law. This ad hoc lower bound is central to the Grossman-Hart solution. As they note (footnote 8, p.47), if it is dropped, additional and inefficient equilibria arise under the dilution rule.

Specifically, suppose $v-\phi<q$. If the raider makes an offer $p$ such that $(v-\phi)^{+} \leq p<q$, there are two equilibrium continuations. In one, no one tenders and the raid fails. In the other, all shareholders tender and receive $(v-\phi)^{+}$. As a consequence, there are two equilibria of the game:

1. In the first equilibrium, shareholders reject any offer below $q$, the raider bids $p=q$ and all shareholders tender.

2. In the second equilibrium, the raider bids $p=(v-\phi)^{+}$and all shareholders tender.

The second equilibrium involves inefficient outcomes. Takeovers in this equilibrium are profitable for the raider whenever $\min \{\phi, v\}>c$. However, efficiency requires that tender offers succeed if and only if $v-c>q$. These inequalities mean the same thing only if $v-q=\min \{\phi, v\}$, which is impossible since $v-\phi<q$ implies $v-q<\min \{\phi, v\}$. In particular, value-reducing bids succeed in this second equilibrium when $\min \{\phi, v\}>c>$ $v-q$.

Thirdly, even preserving the lower bound (12) on admissible offers, Bagnoli and Lipman (1988) identify an inefficiency with the Grossman-Hart solution in a finite-shareholder setting if restricted offers are considered. Suppose $v<\phi$ and the raider makes a conditional and restricted offer to buy exactly 50 percent of the shares at a price $p=q$. Assume that pro-rating occurs if more than 50 percent of shares are tendered. Since $v<\phi$ implies all 
non-tendering shareholders receive zero, it is immediate that a strategy of everyone tendering is a Nash equilibrium. The payoff to the raider in this equilibrium is $v-q / 2-c$ which can be positive even if $v<q$; thus, value-reducing takeovers are possible.

Restricted or conditional offers do not, however, affect the efficiency of outcomes under our freezeout rule (5). Under dilution, inefficiency arises because dilution enables the raider to effect a wealth transfer from minority shareholders to himself, which subsidizes the payment made to tendering shareholders. Under the freezeout rule, the "worst" damage that can be inflicted on the minority shareholders is to buy them out at the price $\max \{r, p\}$. Wealth transfers from minority shareholders to the raider are infeasible, so value-reducing takeovers become impossible.

\section{Exclusion, Takeover Premia, and Efficiency}

The analysis above has the counterfactual implication that the takeover premium - the excess of the tender offer over the pre-offer share price- is zero under the freezeout rule, as it is also under the Grossman-Hart rule. This raises the question of how takeover premia may be generated under exclusion and how this will affect the efficiency of the exclusionary rule. We examine these questions here. The first part of the section discusses Fishman's (1989) model of multiple raiders and the second part looks at the moral hazard model of Burkart, Gromb, and Panunzi (1998).

\section{A. Multiple Raiders and Takeover Premia}

Fishman's (1989) model involves two raiders who move sequentially. Raider $i$ must pay a cost $c_{i}$ to identify the value $v_{i}$ of the firm to himself. Raiders' valuations are private knowledge, but their bids signal information about these quantities. Raider 1 moves first,

observes $v_{1}$, and makes a tender offer. Raider 2 sees the offer and decides whether to pay $c_{2}$, observe $v_{2}$, and then enter. If both raiders enter, an English-auction determines the final outcome. If not, Raider 1's bid stands and shareholders must decide whether to tender. 
Fishman eliminates free-riding by assuming that shareholders tender to the raider offering the higher bid provided it exceeds a threshold value, but similar equilibria arise in his model with our freezeout rule. In equilibrium, pre-emptive bidding by the first raider and Bertrand competition if both raiders enter create a takeover premium.

Reflecting this takeover premium in expectation, equilibrium share prices $r$ will exceed q. This affects the efficiency of freezeouts. For expositional simplicity, we take the costs $c_{i}$ to be zero in this discussion. Under our freezeout rule, an offer below $r$ cannot succeed since non-tendering shareholders are guaranteed at least $r$. If some raider values the firm at more than $r$, then a takeover will occur at a tender price of at least $r$ (the actual takeover premium will depend on how many raiders enter). However, if all raiders' valuations are below $r$ but at least one raider's valuation satisfies $q<v<r$, no bid is made even though $v>q$ implies the takeover would be value improving.

This appears to suggest some inefficiency under freezeouts, but is actually indicative of a more fundamental problem arising under any exclusionary device when $r>q$. Since raiders will not make tender offers above $v$, the only way to ensure all value-improving takeovers succeed, including those where $r>v>q$, is to guarantee the success of some tender offers at prices $p<r$. Such negative takeover premia are, however, unreasonable and unlikely to be legally feasible.

The definition of efficiency must therefore be revised to exclude this possibility. Call a mechanism constrained efficient if takeovers succeed whenever they are value-improving and do not involve negative premia, i.e., takeovers are attempted and succeed (at prices $p \geq r$ ) whenever $v \geq r$. Constrained efficiency is the most one can expect if negative 
takeover premia are disallowed. It is clear from the above discussion that freezeouts are constrained efficient. ${ }^{10}$

\section{B. Moral Hazard, Takeover Premia, and Freezeouts}

Burkart, Gromb, and Panunzi (1998) describe a model with a single raider in which takeover premia arise in the absence of freezeouts. They argue that introducing freezeouts in this setting increases the takeover premium. We show below that this conclusion is incorrect: freezeouts eliminate the takeover premium in this model, and result in outcomes that are fully efficient.

Burkart, Gromb, and Panunzi normalize $q$ to zero; this ensures that only bids $p \geq q$ occur since negative bids are not possible. The raider in their model can effect an increase in firm value of up to $v$, but there is moral hazard after a successful takeover. The raider may choose $\phi \in[0,1]$ to extract private benefits of $b(\phi) v$ at the cost of increasing the firm value by only $(1-\phi) v{ }^{11}$ Because of free-riding, shareholders tender only if the raider's offer equals the anticipated post-takeover value of the firm. Thus, the raider cannot profit on the shares purchased through the tender offer. Nonetheless, a takeover may still be profitable if the private benefits exceed costs; thus, moral hazard may resolve the free-riding problem.

The extraction of private benefits is assumed to be inefficient $(b(\phi)<\phi)$ and this creates an upward-sloping "supply curve" in tendering: Rational shareholders anticipate that the larger the fraction of the post-takeover firm owned by the raider, the less the private benefits extracted, and so the higher the post-takeover firm value. Thus, the tender price $p^{\alpha}$ at which the raider can buy a fraction $\alpha$ of the shares increases in $\alpha$. It follows that the raider's gains are maximized when he buys the 50 percent minimum needed for control.

Since $p^{50 \%}>0$, there is a takeover premium in the sense that tendering shareholders receive more than the firm is worth under incumbent management.

Burkart, Gromb, and Panunzi then suggest that freezeout rules can increase both the takeover premium and social welfare in this setting. Their arguments may be summarized 
as follows. Consider a freezeout mechanism in which non-tendering shareholders can be frozen out at $p$ but only if the raider owns at least a fraction $f$ of the firm where $f$ may be larger than 50 percent. ${ }^{12,13}$ At least some raiders who earlier opted to stay out or to buy 50 percent of the shares (at a price of $p^{50 \%}$ ) will now find it attractive to switch to paying

$p^{f}$, buying $f$, and effecting a freezeout. When $f>50$ percent, we have $p^{f}>p^{50 \%}$ by the arguments of the previous paragraph, so the takeover premium increases under freezeouts. Social welfare also increases, since those raiders effecting a freezeout will own 100 percent of the firm and so will not extract private benefits.

These arguments assume that the raider must pay $p^{f}$ to buy the fraction $f$ necessary to effect a freezeout. This appears incorrect: the supply curve $p^{\alpha}$ is based on free-riding considerations whereas free-riding is not a possibility under freezeouts. Indeed, regardless of $f$, it is easily seen that the following is an equilibrium under freezeouts: the raider makes an offer of $\epsilon>0$ for arbitrarily small $\epsilon$ and all shareholders tender. Free-riding by not tendering is not an option since non-tendering shareholders are frozen out at the tender price. This equilibrium is clearly preferable for the raider to all other alternatives. It is efficient since the raider owns 100 percent of the firm. Thus, there are no takeover premia in the Burkart, Gromb, and Panunzi model under freezeouts, though freezeouts do increase welfare.

\section{The Legal Environment}

Our proposed freezeout mechanism is consistent with both the law and the practice of the treatment of non-tendered shares in the U.S. Tender offers are normally structured as follows. A raider makes a tender offer $p$ for all shares. The offer is conditioned on the raider obtaining at least a majority voting control of the target. In the offer, the raider announces that, as a second step after the offer is completed, the target will be merged into a shell company, fully owned by the bidder. In that "freezeout" merger, the shares held by the non-tendering shareholders are automatically converted into rights to receive the merger 
consideration $(p)$ and the acquirer obtains full ownership of the target. For example, all 13 tender offers made by unaffiliated third parties for the stock of target companies between January and May 2002 followed this pattern. ${ }^{14}$

This practice is sanctioned by law. The law specifically affords holders of a majority of shares the power to approve freezeout mergers against the opposition of holders of a minority of shares. ${ }^{15}$ Although minority shareholders enjoy certain legal protections, from a practical perspective these protections offer non-tendering shareholders no effective legal recourse against freezeout mergers that are structured as a follow-up to, and are on the same terms as, a tender offer, i.e., at $p$ in our notation.

We describe below the legal rights available to non-tendering shareholders - appraisal rights and suits for breaches of fiduciary duties - focusing on the law of Delaware, where well over half of public companies are incorporated. The law of other states does not differ significantly from Delaware law. These legal rights protect shareholders against freezeouts at a price below the pre-offer share price $r$. However, if the freezeout is at an offer price $p$ that exceeds $r$, these rights afford no recourse to obtaining higher compensation. This leads to our freezeout rule $\max \{p, r\}$.

\section{A. Appraisal Rights}

Shareholders are entitled to seek a judicial appraisal of their shares. ${ }^{16}$ In an appraisal action, a shareholder receives the fair value of her shares as assessed by the court instead of the consideration offered in the freezeout merger. Delaware law provides that this value is to be assessed exclusive of any element of value arising from the accomplishment or expectation of the merger. ${ }^{17}$ In practice, shareholders have no reason to expect that the court's appraisal will be larger than an offer price which exceeds the pre-offer share price.

Hence, appraisal rights do not provide effective recourse against a raider that pursues a freezeout merger at such a tender offer price, and, indeed, shareholders hardly ever exercise 
their appraisal rights. The existence of this right, however, ensures that non-tendering shareholders will not receive less than the pre-offer share price.

\section{B. Suits for Breaches of Fiduciary Duty}

Dissenting shareholders can challenge the freezeout merger by suing the raider for breach of fiduciary duty. Such suits relate to self-interested transactions such as a freezeout merger between the target and a company controlled by the raider. In practice, however, raiders can and do insulate freezeout mergers against such challenges.

In a friendly tender offer, which happens in the great majority of takeovers (Schwert (2000)), the raider normally negotiates the terms of the freezeout merger and signs a merger agreement with the target's board prior to making the offer. Since the raider does not control the target at the time of signing the merger agreement, the agreement cannot be challenged as self-dealing even though the raider will control the company by the time shareholders vote on the merger.

Takeovers that start as hostile often end up being negotiated and the raider reaches an agreement with the target's board, which can insulate it from being sued by nontendering shareholders. But even if no merger agreement is signed prior to the tender offer, it is difficult to challenge the merger if the merger consideration is equivalent to the consideration in the tender offer. A court would give substantial weight to the fact that a majority of target shareholders indicated their approval of the transaction by tendering their shares. To our knowledge, there has been no instance in which a raider was held to have violated its fiduciary duties by effecting a second step freezeout merger as a follow-up to, and on the same terms as, a first step tender offer.

Finally, we note that legal regulation of controlling shareholders has not sanctioned

the kind of dilution suggested by Grossman and Hart. Such a transfer would constitute a breach of the raider's duty of loyalty and would subject the raider to legal sanctions. 


\section{Concluding Remarks}

In this paper, we define a specific freezeout mechanism that is consistent with the law and practice of tender offers in the U.S. We show that our mechanism guarantees desirable normative properties in the context of the Grossman-Hart (1980) model of a widely dispersed firm as well as in several modifications of the model discussed in the literature including large shareholdings, asymmetric information, post-takeover moral hazard and risk-arbitrage. In all cases, our rule admits a unique equilibrium which is ex post efficient (i.e., takeovers succeed if and only if the value of the raider-run firm exceeds its value under current management) and ex ante firm-value maximizing. Our mechanism is also superior to the Grossman-Hart alternative of dilution on several grounds including legal admissibility, information requirements, and efficiency of outcomes.

A counterfactual implication of this analysis is that our mechanism, as also the Grossman-Hart dilution rule, generates a zero takeover premium. A positive takeover premium arises if there is competition between raiders. In this case, our mechanism is constrained efficient: Takeovers succeed when and only when at least one raider values the firm at more than its pre-offer share price. No mechanism, including Grossman-Hart's, can be fully efficient here unless negative takeover premia are allowed.

Several open questions remain. One is to incorporate an active role for management in the takeover process, such as the use of defensive measures in bargaining for a higher offer price. A related issue concerns the impact of capital structure choices by incumbent management and/or the raider. Third, since payoffs to non-tendering shareholders under our mechanism depend on the pre-offer share price, there is a question of possible price manipulation. Fourth, we showed that factors such as asymmetric information lack force in the Grossman and Hart model under freezeouts; are there richer model structures under which these factors have a non-trivial impact? Lastly, we have offered competition among raiders as one possible explanation of takeover premia in the presence of freezeouts. The identification of other possible explanations remains. 


\section{Notes}

${ }^{1}$ The freezeout mechanism in these papers differs from ours in some details. See Sections II.C and IV.

${ }^{2}$ Other work includes Yarrow (1985) on the role of freezeouts in resolving the free-rider problem; Hermalin and Schwartz (1996) who present a model of freezeouts by controlling shareholders and argue that awarding pre-freeze-out market price in an appraisal proceeding creates efficient incentives to invest; Bebchuk and Hart (2001) who compare three mechanisms - proxy fights, takeovers, and a combination of proxy fights and takeovers - in corporate control contests; and Mueller and Panunzi (2003) who investigate the role of debt-financing in takeovers and show that the raider's incentives lead him to use more debt than is socially optimal.

${ }^{3}$ The raider arrives with probability one, but bids only if it is profitable to do so (see below); thus, his observed arrival depends on his valuation of the firm relative to its value under current management.

${ }^{4}$ The common knowledge assumption is unnecessary for our freezeout mechanism. See Section II.A for details.

${ }^{5}$ This formulation of the manager's actions and preferences is from Grossman and Hart; see there for further motivation and details. In general, management has two potential roles associated with takeovers. One is creating value for existing shareholders ( $q$ in our model); this is an important part of our analysis. The other is being agents of shareholders in the takeover process. Intuition and empirical evidence (e.g., Long and Walkling (1984)) suggest that managerial actions in this regard depend on the extent of alignment of managementshareholder interests (though Schwert (2000) presents evidence suggesting that "hostility" in takeovers may just be part of a bargaining process). As with much of the literature on takeovers (including Grossman-Hart), our paper does not explicitly model the possible misalignment of interests, so there is no role for management as representing shareholders. 
${ }^{6}$ There are formal technical problems in dealing with conditional or restricted offers in a setting with a continuum of shareholders. See, e.g., Bagnoli and Lipman (1988, footnote 29). We consider restricted offers in Section III in the context of a firm with a finite set of "large" shareholders.

${ }^{7}$ Our paper examines tender offers and not mergers. In a tender offer, the decision on tendering is made by individual shareholders. Fishman (1988, p. 53) suggests that in mergers it is management instead that makes the accept/reject decision (though shareholders are required by law to approve the merger subsequently). In a merger, the free-riding problem is absent since stockholders will collectively vote in favor of a value-increasing offer, i.e., one where $v \geq q$. Tendering after the merger is, however, still regulated by the freezeout rule; see Section V.

${ }^{8}$ Allowing the freezeout rule to depend on $r$ raises the concern of manipulation of share price by either party. For the raider, a lower share price $r$ is unambiguously better. For shareholders, there is a trade-off: A higher share price provides a higher floor value from a takeover but reduces the likelihood of a takeover. Formal modelling of this issue requires introducing information sets and trading rules that take us well beyond the scope of this paper.

${ }^{9} \mathrm{~A}$ tender offer of $p$ in which non-tendering shareholders are frozen out at $r \leq p$ is similar to two-tier offers. Bradley, Desai, and Kim (1988) show that such offers create pressure to tender, overcoming the free-rider problem. Fair-price provisions (in corporate charters or in state laws) requiring equal compensation for all shareholders, and other measures such as poison pills, have made two-tier offers extinct in hostile tender offers.

${ }^{10}$ The Grossman-Hart mechanism too will result in $r>q$ because of the Bertrand competition among raiders. However, since feasible bids are required only to satisfy $p \geq q$, takeovers will succeed in this mechanism if at least one raider's value exceeds $q$. This implies that takeovers will succeed at negative premia. Outcomes no longer coincide under 
freezeouts and Grossman and Hart's dilution since the likelihoods of takeovers succeeding differ.

${ }^{11}$ The Burkart, Gromb, and Panunzi model is thus akin to Grossman-Hart with costly dilution, i.e., dilution of firm value of $\phi v$ results in the raider receiving only $b(\phi) v$ with $b(\phi)<\phi$.

${ }^{12}$ Since $p \geq q$ in this model, freezing out non-tendering shareholders at $p$ is equivalent to freezing them out at $\max \{p, q\}$.

${ }^{13}$ Our rule sets $f=50$ percent. Most U.S. states (including Delaware) use $f=50$ percent, though some such as Alaska and Texas set $f=2 / 3$. Corporations can also impose supermajority requirements through their charters but few do so: Coates (1998) reports that of 1,500 S\&P firms, fewer than 100 had such requirements.

${ }^{14}$ Source: Securities Data Corporation and the actual tender offers.

${ }^{15}$ In the first part of the 20th century, states permitted merger by majority vote, which departed from the 19th century requirement of unanimous approval by all shareholders. The aim was to facilitate corporate reorganizations that were called for by the economic conditions of the day (Levy (1930)). At about the same time, Levy writes (pp. 420-421): "... it was also realized that it was necessary to afford some relief to dissenters ... The result in most jurisdictions, was a compromise conferring on the dissenters the right to receive the cash value of their stock and providing for an appraisal where no agreement could be reached."

${ }^{16}$ Appraisal rights are available in Delaware in cash mergers and in so-called short-form mergers. To effect a short-form merger, the raider must own at least 90 percent of the target's stock after the tender offer.

${ }^{17}$ Delaware General Corporation Law, 262(h). In particular, the raider's proposed strategy for running the company does not affect the value awarded in the appraisal unless the 
raider begins to implement that strategy prior to the freezeout merger: See Cede \& Co. v. Technicolor, Inc., 634 A.2d 345 (Del. 1993). 


\section{REFERENCES}

Bagnoli, Mark and Barton Lipman, 1988, Successful takeovers without exclusion, Review of Financial Studies 1(1), 89-110.

Bebchuk, Lucian A., 1989, Takeover bids below the expected value of minority shares, Journal of Financial and Quantitative Analysis 24, 171-184.

Bebchuk, Lucian A. and Oliver Hart, 2001, Takeover bids vs. proxy fights in contests for corporate control, mimeo, Harvard University.

Bradley, Michael, Anand S. Desai, and E. Han Kim, Synergistic gains from corporate acquisitions and their division between the stockholders of target and acquiring firms, Journal of Financial Economics 21, 3-40.

Burkart, Michael, Denis Gromb and Fausto Panunzi, 1998, Why higher takeover premia protect minority shareholders, Journal of Political Economy 106, 172-204.

Coates, John C., 1998, The contestability of corporate control: A critique of the scientific evidence on takeover defenses, Working Paper, Harvard Law School.

Cornelli, Francesca and David D. Li, 2001, Risk-arbitrage in takeovers, mimeo, London Business School \& Hong Kong University of Science and Technology.

Feldman, Mark and Christian Gilles, 1985, An expository note on individual risk without aggregate uncertainty, Journal of Economic Theory 35.

Fishman, Michael J., 1989, Preemptive bidding and the role of the medium of exchange in acquisitions, Journal of Finance 44, 41-57.

Giammarino, Ronald M. and Robert L. Heinkel, 1986, A model of dynamic takeover behavior, Journal of Finance 51, 465-480.

Gomes, Armando, 2001, Takeovers, freezeouts, and risk-arbitrage, Working Paper, University of Pennsylvania.

Grossman, Sanford J. and Oliver Hart, 1980, Takeover bids, the free-rider problem, and the theory of the corporation, Bell Journal of Economics 11, 42-64. 
Hermalin, Benjamin and Alan Schwartz, 1996, Buyouts in large companies, Journal of Legal Studies 25, 351-370.

Hirshleifer, David and Sheridan Titman, 1990, Share tendering strategies and the success of hostile takeover bids, Journal of Political Economy 98, 295-324.

Judd, Ken, 1985, The Law of Large Numbers with a continuum of i.i.d. random variables, Journal of Economic Theory 35, 19-25.

Levy, Irving J., 1930, Rights of dissenting shareholders to appraisal and payment, Cornell Law Quarterly 15, 420-444.

Long, Michael and Ralph Walkling, 1984, Agency theory, managerial welfare and takeover bid resistance, Bell Journal of Economics 5, 54-68.

Mueller, Holger and Fausto Panunzi, 2003, Tender offers and leverage, mimeo, Stern School of Business, New York University.

Ravid, S. Abraham and Matthew Spiegel, 1999, Toehold strategies, Takeover laws and rival bidders, Journal of Banking and Finance 23, 1219-1242.

Schwert, G. William, 2000, Hostility in takeovers: In the eyes of the beholder? Journal of Finance 55, 2599-2640.

Shleifer, Andrei and Robert W. Vishny, 1986, Large shareholders and corporate control, Journal of Political Economy 94, 461-488.

Yarrow, Graham K., 1985, Shareholder protection, compulsory acquisition, and the efficiency of the takeover process, Journal of Industrial Economics 34(1), 3-16. 